\title{
Análise étnico-racial de imagens em livros didáticos de Biologia
}

\author{
Ethnic-racial analysis of images in Biology textbooks
}

\author{
Michele Assis de Oliveira \\ Mestranda em Educação em Ciências \\ Universidade Federal do Rio Grande do Sul - UFRGS. \\ Porto Alegre, Rio Grande do Sul - Brasil. \\ micheleassisdeoliveira@gmail.com \\ Russel Teresinha Dutra da Rosa \\ Doutora em Educação \\ Universidade Federal do Rio Grande do Sul - UFRGS. \\ Porto Alegre, Rio Grande do Sul - Brasil. \\ russel.rosa@ufrgs.br \\ Tanara Forte Furtado \\ Doutoranda em Educação \\ Universidade Federal do Rio Grande do Sul - UFRGS. \\ Porto Alegre, Rio Grande do Sul - Brasil. \\ tanara.forte.furtado@gmail.com
}

Resumo: O presente trabalho resulta de uma pesquisa de caráter qualitativo. Analisam-se imagens humanas, sobretudo de pessoas negras e indígenas, presentes em livros didáticos de Biologia publicados antes e após a implantação do Programa Nacional do Livro Didático do Ensino Médio, em 2009, e as obras incluídas no Programa Nacional do Livro Didático, de 2018. Os livros de Biologia recorrem a diversas fotografias e representações de seres humanos, cujos contextos socioculturais importam para a manutenção ou transformação da realidade social. Diante da predominância da representação descontextualizada de determinados grupos étnicos, ocasionada pela branquitude acrítica, este estudo tem o objetivo de verificar se a forma de representação plural, regulamentada em editais, está presente nos livros didáticos atuais. Conclui-se que, conquanto tenha havido ligeira melhora na última década, a abordagem dos livros didáticos distribuídos às escolas públicas ainda minimiza a promoção da equidade étnico-racial.

Palavras chave: diversidade; educação; ERER; inclusão; livro didático.

Abstract: The present text is the result of a qualitative research. Human images are analyzed, especially of black and indigenous people, present in Biology textbooks published before and after the implementation of the National High School Textbook Program, in 2009, and the works included in the National Textbook Program, from 2018. Biology books uses several photographs and representations of human beings, whose sociocultural contexts matter for the maintenance or transformation of social reality. Given the predominance of the decontextualized representation of certain ethnic groups, caused by uncritical whiteness, this study aims to verify if the plural form of representation, regulated in public notices, is present in current textbooks. It is concluded that, although there has been a slight improvement in the last decade, the approach of textbooks distributed to public schools still minimizes the promotion of ethnic-racial equity.

Key-words: diversity; education; multicultural education; inclusion; textbook.

Cite como

(ABNT NBR 6023:2018)

OLIVEIRA, Michele Assis; ROSA, Russel Teresinha Dutra; FURTADO, Tanara Forte. Análise étnico-racial de imagens em livros didáticos de biologia. Dialogia, São Paulo, n. 39, p. 1-18, e20389, set. /dez. 2021. Disponível em: https://doi.org/10.5585/39.2021.20389.

American Psychological Association (APA)

Oliveira, M. A., Rosa, R. T. D., \& Furtado, T. F. (2021, set./dez.) Análise étnico-racial de imagens em livros didáticos de Biologia. Dialogia, São Paulo, 39, p. 1-18, e20389. https://doi.org/10.5585/39.2021.20389. 


\section{Introdução}

O estudo ${ }^{1}$ que deu origem a este artigo teve como objetivo comparar como são representadas as populações negras e os povos originários antes e após a implantação do Programa Nacional do Livro Didático. O propósito foi verificar a realização de avaliação das publicações, de acordo com os critérios dos editais de 2007 e de 2018, na quantidade de imagens e na forma de representação das pessoas nelas contidas.

Analisamos livros didáticos de Biologia do Ensino Médio produzidos antes da implantação do Programa Nacional do Livro Didático do Ensino Médio (PNLEM), por meio do edital publicado em 2007, bem como algumas das primeiras obras selecionadas de acordo com os critérios deste documento, recomendadas no Catálogo de Biologia do Programa Nacional do Livro para o Ensino Médio (PNLEM 2009), e as obras de Biologia incluídas no guia de livros didáticos do Ensino Médio do Programa Nacional do Livro Didático (PNLD 2018).

O Brasil é a expressão da diversidade, tendo sido forjado a partir do encontro entre povos originários, europeus, orientais e africanos de diferentes matrizes étnicas e culturais. Porém, as populações negra e indígena são exploradas e silenciadas desde a colonização, resultando em processos de exclusão ainda persistentes, o que torna urgente a visibilidade e valorização desses grupos.

É necessário pensar sobre o racismo e inserir uma visão afirmativa sobre as contribuições sociais, culturais e religiosas das diversas matrizes civilizatórias que compõem o nosso povo, de modo que sejam capazes de contribuir para o processo de construção e afirmação da identidade e da autoestima dos alunos - crianças e adolescentes - descendentes de povos negros e indígenas.

A representação dessa parcela da população como grupos minoritários em livros didáticos é fortemente atravessada pela branquitude. De acordo com Bento et al. (2002), essa conceituação pode ser definida como "[...] traços da identidade racial do branco brasileiro a partir das ideias sobre branqueamento" (BENTO et al., 2002, p. 29). Já o pesquisador Lourenço Cardoso (2010) estabelece uma diferenciação entre duas categorias no intuito de situar o fenômeno no quadro social brasileiro: branquitude crítica e branquitude acrítica. Segundo ele:

[...] a branquitude crítica refere-se ao indivíduo que desaprova publicamente o racismo. Já a branquitude acrítica refere-se ao indivíduo ou coletividade que luta pela manutenção do status de superioridade racial branca. 'Apesar do apoio às práticas racistas ou da inação diante delas, a branquitude acrítica pode não se considerar racista porque, segundo sua concepção, a superioridade racial branca seria uma realidade inquestionável' (CARDOSO, 2010, p. 63).

\footnotetext{
${ }^{1}$ Este artigo foi elaborado a partir de pesquisa desenvolvida para a produção do Trabalho de Conclusão do Curso de Graduação em Licenciatura em Ciências Biológicas do Instituto de Biociências da Universidade Federal do Rio Grande do Sul, apresentado em janeiro de 2018.
} 
Portanto, essa perspectiva de representação está repleta de marcadores que evidenciam o ideal de branqueamento ${ }^{2}$ difundido no imaginário popular, responsável por naturalizar a associação dos povos negros e indígenas a papéis de menor prestígio social. Dessa forma, dificulta-se sua legitimação e reconhecimento como cidadãos portadores de direitos plenos. A não existência dos saberes do povo negro e indígena se faz presente quando suas culturas são tematizadas via folclorização, exotismo ou negação (GOMES, 2017).

É importante perceber a predominância da representação descontextualizada de grupos étnicos autóctones nos diferentes meios de comunicação, ocupando posições como a de artesão, pescador, caçador e curandeiro. Torna-se necessário verificar se essa forma de representação sofreu modificações ou se ainda está presente nos livros didáticos atuais.

A escolha pelas populações indígenas se deu pelo fato de que as pessoas, quando ouvem falar dos povos originários ou veem alguma imagem em que estão representados, não os diferenciam por nações e/ou costumes, caracterizando-os de forma generalista como "índios". Da mesma forma, quando nos deparamos com imagens do povo negro, constatamos um quantitativo reduzido de imagens. Além disso, é ausente o diálogo entre as relações étnico-raciais e os referenciais de pertencimento dos negros/as. Ainda é necessária uma maior valorização da produção cultural, superando representações que ocorrem apenas no sentido folclórico, afinal, uma educação que promova a autoestima da criança negra - e, nesse caso, também da indígena - é, para Romão (2001), aquela que supera os limites de inserção da temática na escola em tópicos especiais ou em datas comemorativas.

É notável que a herança carregada possa conduzir à discussão de saberes tradicionais, como o uso alimentar ou medicinal de plantas, por exemplo, que podem, inclusive, contribuir para inovações científicas (VERRANGIA; SILVA, 2010).

A proposta metodológica do estudo constitui-se da análise qualitativa de livros didáticos, a fim de verificar o cumprimento de políticas públicas de reparação, reconhecimento e valorização das culturas afro-brasileira e indígena. Também se buscou identificar a promoção da reeducação para as relações étnico-raciais.

\footnotetext{
2 São designados como ideal de branqueamento os resquícios e as evidências de políticas - adotadas pelo Estado brasileiro (1888-1920) -, por meio das quais pretendia-se extinguir a população negra do País, substituindo-a por indivíduos miscigenados de pele clara. Ainda que o Estado tenha abandonado oficialmente tal política, as práticas e os discursos se tornaram hegemônicos a ponto de ainda hoje povoarem significativamente o imaginário social.
} 


\section{O livro didático}

O livro didático é a ferramenta mais acessível em termos de recursos pedagógicos em escolas públicas de Educação Básica. Por isso, torna-se a principal referência para trabalhar o ensino de Ciências e de Biologia.

O PNLEM foi implementado a partir da aprovação da Lei n. 11.194 de 2007, que regulamentou o Fundo de Manutenção e Desenvolvimento da Educação Básica e de Valorização dos Profissionais da Educação (FUNDEB) (BRASIL, 2008a). A lei possibilitou a destinação de recursos para avaliação, aquisição e distribuição de livros didáticos para o Ensino Fundamental e também para o Ensino Médio. A partir do edital de 2007 do PNLEM, foram aprovadas nove coleções didáticas de Biologia para distribuição no ano de 2009 (BRASIL, 2008b). Desde então, foram realizadas quatro avaliações de livros didáticos de Biologia para a distribuição nos anos de 2009, 2012, 2015 e 2018 (BRASIL, 2017).

A aprovação das obras submetidas ao edital PNLEM 2007 estava condicionada ao atendimento de diversos critérios, entre os quais um que objetivava evitar a veiculação de preconceitos e estereótipos étnico-raciais e a possibilidade de exclusão de obras que veiculassem qualquer tipo de preconceito, conforme o trecho a seguir:

\footnotetext{
- privilegiar um determinado grupo, camada social ou região do País;

- veicular preconceitos de origem, cor, condição econômico-social, etnia, gênero;

- orientação sexual, linguagem ou qualquer outra forma de discriminação (BRASIL, edital PNLEM, 2007).
}

Esse Edital também indicava preocupação com a representação da pluralidade social: “[...] estimular o convívio social e o reconhecimento da diferença, abordando a diversidade da experiência humana e a pluralidade social, com respeito e interesse [...]” (BRASIL, edital PNLEM, 2007).

Já o edital PNLD 2018 detalhava e especificava ainda mais os critérios de avaliação, com a finalidade de contribuir para a promoção de transformações das relações étnico-raciais e de gênero, no sentido de buscar maior equidade. O item 3.4.1, que trata dos princípios e critérios de avaliação para a área de Ciências da Natureza e Biologia, induzia uma seleção de imagens que deveria retratar a diversidade étnica da população brasileira e a pluralidade social e cultural do País.

3.4.1 [...] A Biologia pode, portanto, contribuir para a valorização dos direitos humanos de respeito à pluralidade e à diversidade de nacionalidade, etnia, gênero, classe social, cultura, crença religiosa, orientação sexual e opção política ou qualquer outra diferença (BRASIL, edital PNLD, 2018). 
Observamos que ambos os editais (PNLEM 2007 e PNLD 2018) demonstraram preocupação em evitar estereótipos raciais e preconceitos. Ademais, o edital PNLD 2018, reiterou a necessidade de que as imagens expressassem a pluralidade étnico-racial e contemplassem as diversidades econômico-social, cultural, de gênero, religiosa e qualquer outra forma de manifestação individual e coletiva. Dessa forma, visava evitar estereótipos e associações que depreciassem determinados grupos ou que desvalorizassem a contribuição dos diferentes segmentos da sociedade.

Do ponto de vista pedagógico, a imagem é veículo de representação de relações sociais e pode simbolizar, de diferentes maneiras, valores com os quais a sociedade se identifica e que reconhece como universais. Assim, pautar os usos e funções da imagem visual no processo de construção de representações sociais reconhecidas como educacionalmente válidas é parte do processo de promoção de equidade. Nesse sentido, é importante analisar como os diferentes grupos étnicos são representados nos livros didáticos por meio de ilustrações, visto seu potencial impacto sobre a construção da identidade dos alunos de ascendência africana, indígena e mestiça, quando não encontram referências positivas sobre sua origem, cultura e história ou são manifestas de modo caricatural, estereotipado e folclorizado (SILVA, 1995).

Freire (2002), em período anterior à implementação do PNLEM 2009, já afirmava que a representação que cada brasileiro tem do indígena é prioritariamente aquela que foi transmitida na sala de aula, com a ajuda do livro didático. Sob o ponto de vista do autor, a escola, longe de informar e formar seus alunos, termina por divulgar uma gama de preconceitos e estereótipos, legitimandoos. Silva (1995), em período ainda anterior ao de Freire, afirma:

[...] o livro didático, de modo geral, omite o processo histórico-cultural, o cotidiano e as experiências dos segmentos subalternos da sociedade, como o índio, o negro, a mulher, entre outros. Em relação ao segmento negro, sua quase total ausência nos livros e a sua rara presença de forma estereotipada concorrem em grande parte para a fragmentação da sua identidade e auto-estima [...] (SILVA, 1995, p. 47).

O livro didático é, ainda hoje, um dos materiais pedagógicos mais utilizados, principalmente nas escolas públicas. Em razão da escassez de recursos diversificados e da elevada quantidade de alunos por turma/sala, o livro muitas vezes constitui a única fonte de leitura para os estudantes oriundos de classes populares (SILVA, 2001).

As imagens, além de serem utilizadas como suporte pedagógico, podem se configurar como objeto de análise e reflexão. A partir daí, emerge a importância de garantirmos a representação positivada de imagens de negros e indígenas em livros didáticos e a criação e realização de estratégias que promovam a reeducação das relações étnico-raciais (ERER). 


\section{Relações étnico-raciais}

As teorias racistas da época colonial, as teorias racialistas (pretensamente não racistas) adotadas no pós-abolição e as políticas excludentes foram a base para a criação de um sistema educacional que tinha como objetivo principal educar para uma identidade nacional branca e de raízes europeias (AMORIM, 2019). A centralidade da cultura europeia no currículo escolar culmina em estereótipos presentes nos livros didáticos ao frequentemente relacionar a população negra e indígena (quando não somente) a fatores negativos, como a escravidão e postos de trabalho com menor status e remuneração, ou exóticos e festivos, como o samba, o carnaval e esportes. Desse modo, os estereótipos presentes nas imagens demonstram o que está no imaginário social formatado desde as bases racistas do escravismo.

Soma-se a essa concepção, o despreparo dos professores para abordar questões relacionadas ao preconceito e à discriminação racial. O resultado dessa operação aditiva é um ciclo de perpetuação do imaginário e de atitudes racistas. Nesse contexto, o ambiente escolar é atravessado por referenciais racistas, que se apresentam sob variadas formas e suportes. Ocorre a reprodução - em um local tido como instância legitimadora de conhecimento - de representações estereotipadas de grupos já fragilizados na sociedade.

$\mathrm{Na}$ década de 1980, o Movimento Negro envolveu-se em diversas mobilizações, que tinham por objetivo denunciar o racismo e a ideologia dominante, expandir a politização das pessoas em torno do conceito de raça, ressignificando-o. O Movimento visava também valorizar a identidade negra em lugares nos quais ela não era considerada ou era invisibilizada, dentre estes, a escola, enquanto instituição responsável (ao menos em tese) pela propagação de princípios de igualdade (GOMES, 2017). A pauta reivindicatória incluiu, entre outras demandas, críticas aos livros didáticos, ao currículo e à formação de professores.

As mudanças sociais e as políticas para os povos negro e indígena se tornaram mais visíveis e concretas na redemocratização (1985), seguidas pelos debates que produziram a Constituição Federal de 1988. Foram garantidos, no texto legal, o direito individual e coletivo em suas vertentes de liberdade de culto religioso, de manifestação e associação, além da definição do racismo como crime inafiançável, afora outros direitos sociais que construíam um espaço legal para a luta pela dignidade desses dois segmentos populacionais brasileiros (BRASIL, 1985).

Em 2001, quando da Conferência Internacional de Durban, na África do Sul, o Estado brasileiro tornou-se signatário da declaração, passando a reconhecer internacionalmente as dimensões institucionais e estruturais do racismo no País e se comprometendo a construir medidas para a sua superação. Dentre estas, situamos as ações afirmativas, que buscaram reservar vagas no 
campo da educação e do emprego, sobretudo, públicos (GOMES, 2017). Tais ações culminaram na implantação da Lei Federal n 10.639/03, que estabelece a obrigatoriedade do ensino de História e Cultura Afro-Brasileira e Africana na Educação Básica, redigindo o artigo 26-A da Lei de Diretrizes e Bases da Educação Nacional (Lei n 9.394/1996 - LDBEN). O artigo ganhou nova redação em 2008, conforme a Lei n 11.645, assim alterado: "Nos estabelecimentos de ensino fundamental e de ensino médio, públicos e privados, torna-se obrigatório o estudo da história e cultura afro-brasileira e indígena” (BRASIL, 2008a).

Da mesma forma, o Parecer CNE/CP 003/2004 regulamentou a alteração trazida à LDBEN e estabeleceu a Resolução CNE/CP n ${ }^{\circ}$ 1/2004 (Diretrizes Curriculares Nacionais para a Educação das Relações Étnico-Raciais e para o Ensino de História e Cultura Afro-Brasileira e Africana), e orientou o atendimento do artigo 26-A em diferentes disciplinas do currículo. São políticas de reparação e valorização que buscam, entre outros objetivos, reeducar os negros/as na sua relação com o corpo e também reeducar a sociedade brasileira no seu olhar sobre o corpo negro (GOMES, 2017).

A regulamentação legal acima citada tem sido considerada na produção dos editais do PNLD e vem orientando as editoras quanto aos critérios de avaliação das obras. Isso potencializa a escola enquanto instituição capaz de contribuir para a construção de uma nova realidade no campo das relações étnico-raciais e como um campo de afirmação de identidades raciais múltiplas e equânimes.

Uma das principais regulamentações legais educacionais da atualidade, a Base Nacional Comum Curricular (BNCC), em sua versão do ano de 2016, apresentou indícios de ter sido construída a partir de observação e consideração dos marcos legais das ações afirmativas mencionadas.

Contudo, a terceira versão da BNCC da Educação Infantil e do Ensino Fundamental, lançada em abril de 2017 pelo Ministério da Educação, não citava tais marcos legais e ainda substituía o termo "racial" pelo termo "cultural" empregando a expressão "étnico-cultural". A omissão quanto à legislação referente à ERER causou estranheza e preocupação. Todavia, quando da aprovação do texto final pelo Conselho Nacional de Educação, em dezembro de 2017, na parte do texto relativa aos temas contemporâneos, a ERER foi citada, mas sem o detalhamento que constava na versão de 2016 e sem ser explicitada nos temas e objetos de estudo da área de Ciências da Natureza. Essas omissões também foram percebidas na versão da BNCC do Ensino Médio, publicada em dezembro de 2018. Tendo em vista a falta de ênfase na ERER, observada no texto da BNCC, há uma grande incerteza e insegurança em relação aos critérios que passarão a ser 
considerados para a avaliação, compra e distribuição de livros didáticos pelo Ministério da Educação nos próximos editais do PNLD.

\section{Procedimentos metodológicos}

Realizamos um estudo qualitativo por meio de análise documental, no qual observamos, descrevemos e quantificamos imagens com representações de pessoas negras e indígenas em livros didáticos de Biologia do Ensino Médio. As obras representam uma amostra de conveniência, constituída por exemplares do acervo de livros didáticos do Laboratório de Ensino da Faculdade de Educação, a Casa de Ofícios, do acervo de professores de Biologia do Colégio de Aplicação da UFRGS e do acervo da professora orientadora da pesquisa. Assim, compusemos uma amostra com os livros de Biologia localizados que eram anteriores ou que faziam parte do PNLEM 2009 e do PNLD 2018.

O conjunto das obras foi constituído por dois livros produzidos antes do PNLEM, sete livros aprovados pelo PNLEM 2009 e 24 livros aprovados pelo PNLD 2018, totalizando, portanto, 33 livros examinados. $\mathrm{Na}$ análise, verificamos se, e de que forma foram atendidos os critérios de avaliação relativos à diversidade étnico-racial. Também examinamos se a existência desses critérios de avaliação produziu mudanças na produção de livros didáticos de Biologia ao longo dos últimos anos em razão da avaliação.

A primeira estratégia analítica tratou de quantificar, em cada livro, o total de fotografias com humanos e, dentre estas, o total de pessoas negras e indígenas representadas. Em um segundo momento, elaboramos uma tabela comparativa entre a totalidade das fotografias de humanos em relação às imagens nas quais foi identificada a presença de pessoas negras e indígenas, destacandose o gênero (masculino ou feminino) e a faixa etária (adulto ou criança), bem como a ocupação das pessoas representadas. A terceira estratégia foi fotografar e descrever as imagens, fotografias e desenhos com representações de pessoas, incluindo o contexto da representação. A partir da análise das descrições, construímos categorias relacionadas às formas recorrentes de representação de negros/as e de indígenas, a fim de compará-las com as representações contidas nas imagens de pessoas brancas. Também apuramos a presença de desenhos esquemáticos, com representação do corpo humano e de órgãos internos, com ilustrações de pele e outros traços fisionômicos, que foram observados quanto a características de populações negras, indígenas ou figuras de pele clara.

A análise se estabeleceu de acordo com os critérios presentes nos editais de 2007 e 2018. O edital de 2007 previa a possibilidade de exclusão de obras que “[...] privilegiassem um determinado grupo, camada social ou região do país, veiculasse preconceitos de origem, cor, 
condição econômico-social, etnia, gênero, orientação sexual, linguagem ou qualquer outra forma de discriminação" (BRASIL, edital PNLEM, 2007, p. 37). Com respeito à expressão da pluralidade da população brasileira, o critério adotado foi o da proporção de acordo com dados do IBGE (2017), segundo os quais aproximadamente 50\% da população brasileira é constituída por mulheres e também cerca de $50 \%$ da população se declara negra (preta ou parda). Assim essa proporção de imagens seria uma representação de pluralidade. Com relação aos indígenas, dado os processos históricos, ainda em curso, de genocídio, a proporção populacional é de menos de 1\% e exatamente por isso, esperava-se que os livros comprometidos com uma educação de promoção do respeito aos povos originários, os representassem numa proporção maior.

O Edital do PNLD 2018, também previa a exclusão de obras que veiculassem preconceitos, indicando que os livros precisavam veicular imagens não estereotipadas dessas parcelas da população e de seus saberes tradicionais, a fim de estabelecer a promoção positiva considerando a participação e o protagonismo em diferentes trabalhos, profissões e espaços de poder (BRASIL, edital PNLD, 2018). Embora esse edital não explicitasse em que consistiria uma representação positiva e não estereotipada, na pesquisa, os critérios adotados para julgar estas representações foram: (1) se o indivíduo representado parecia estar em situação de protagonismo em contextos profissionais, de produção de conhecimento, em espaços de atuação política e/ou de exercício de poder; ou se era passivo, representado como paciente em um consultório, ou como objeto de conhecimento; (2) se o indivíduo estava inserido em contexto acadêmico como estudante, ou profissional de nível superior - indicando maior nível de escolarização -; ou se realizava trabalhos subalternos, geralmente braçais em meio rural ou urbano (DUBAR, 2012); (3) se o indivíduo aparentava ser saudável, ou ter hábitos alimentares saudáveis, em atividades recreativas e de socialização que promovem a saúde; ou se era representado como portador de uma doença, ou inserido em um ambiente degradado.

\section{Resultados e discussão}

Nos dois livros anteriores à implantação do PNLEM 2009, havia apenas três fotografias de pessoas. No livro de 1983, tratava-se de uma única fotografia de mulher - branca e com hipertireoidismo. No livro de 2000, havia uma foto de Louis Pasteur - cientista francês atuante no final do século XIX - e uma foto de uma mulher grávida, de pele branca, situada no capítulo de genética do desenvolvimento. É interessante observar que, nos dois casos, as mulheres foram representadas tão somente enquanto objetos de estudo, enquanto o homem foi retratado como um sujeito ativo na produção de conhecimento científico, positivamente. 
Analisamos, a partir dos critérios estabelecidos no edital de 2007 (os quais orientaram a avaliação das obras submetidas no PNLEM 2009), sete dos 17 livros aprovados. Neles, foram localizadas 131 fotos de pessoas. 26 fotos (20\%) representavam pessoas negras e não havia nenhuma foto de pessoa indígena.

Já o edital do PNLD 2018, além de prever a exclusão de obras que veiculassem preconceitos, indicava que as obras precisavam veicular imagens positivas dessas parcelas da população (negros/as e indígenas). A partir deste edital, foram aprovadas dez coleções de livros didáticos de Biologia. Dentre estas, foram analisadas oito, totalizando 24 livros. Foram encontradas 425 fotos de seres humanos, sendo 112 (26\%) de pessoas negras e 20 (5\%) de pessoas indígenas.

Também comparamos as fotografias de pessoas negras e indígenas em uma coleção completa, aprovada no PNLEM 2009, e em oito coleções completas aprovadas no PNLD 2018. Embora o número de representações de pessoas negras aumente de 20\%, em 2009, para 26\% em 2018, não se pode considerar como um aumento expressivo, considerando a proporção de negros na população brasileira.

Entre as nove fotos de pessoas negras na coleção completa de 2009, seis eram de pessoas adultas e três de crianças. Das seis pessoas adultas, todas eram homens. Das três crianças, duas fotos eram de meninos e uma de menina. A coleção não trouxe nenhuma representação de pessoa indígena.

Nas oito coleções completas de 2018, foram localizadas 89 fotos de pessoas negras adultas e 25 fotos de crianças negras. Das adultas, 37 eram homens e 52 eram mulheres. Dentre as crianças, 13 eram meninos e 11 eram meninas, sendo que em uma das fotos não foi possível determinar o gênero, visto se tratar apenas do pé de uma criança negra e não constar especificações na legenda.

Até 2009, as pessoas negras apareceram somente em três fotografias de atletas e em duas fotos de recicladores de lixo. Nas obras do PNLEM 2009, além de não existir representação de pessoa negra em profissões que exigem formação de nível superior, as pessoas representadas ou realizavam atividades físicas ou estavam em situação de vulnerabilidade social, com imagens diretamente ligadas à questão da pobreza. Já nos livros aprovados pelo PNLD 2018, ocorrem representações contextualmente diversificadas, tais como: profissionais de nível superior, estudantes e pessoas em situação de vida saudável. Assim, constatamos um total de 113 (81\%) imagens positivas de pessoas negras em 2018.

Nas coleções de 2018, foram observadas a presença das seguintes profissões nas fotografias de pessoas negras: 15 atletas, um comerciante, uma enfermeira, nove estudantes, um geógrafo, três 
médicas, um motorista, três pesquisadores e um professor. No total, são oito fotografias de profissionais com formação em nível superior e nove de estudantes, totalizando 17 fotografias.

A figura do atleta negro foi a mais presente em todas as coleções de 2018. Portanto, não surpreende o fato de que as poucas representações de pessoas negras, contidas também em livros aprovados no PNLEM 2009, tenham reproduzido a recorrente figura do negro jogador e maratonista. Essa representação tem um sentido ambivalente: embora as imagens de atletas sejam positivas, seu estereótipo tem origem na valorização da força física do negro, em prejuízo de sua inteligência (MARTINS, 2009). Por isso, é importante considerar que o valor dos atletas negros nos esportes sempre foi reconhecido, ao mesmo tempo que tal condição não contribui para seu reconhecimento na qualidade de sujeito portador de direitos e cidadania plenos.

Quanto aos desenhos esquemáticos, em dois exemplares do PNLEM 2009 ocorreram representações de pessoas negras no capítulo sobre verminose, mais especificamente no ciclo da tênia.

Nas coleções de 2018, foi possível verificar as seguintes representações: uma pesquisadora, a diversidade de tons de pele fazendo inferências a contextos genéticos, representações demonstrando a diversidade cultural, representações simbolizando a inclusão de pessoas com necessidades especiais, contextualizações sobre sustentabilidade ambiental e sexualidade responsável e 23 desenhos esquemáticos, indicando órgãos anatômicos em corpos da etnia negra ou indígena. É importante mencionar a representação de corpos negros para a indicação anatômica de órgãos internos nas coleções do PNLD 2018, registro inexistente nos livros aprovados no PNLEM 2009.

Observamos também que passaram a existir representações de povos indígenas nas coleções de 2018, ausentes até 2009. Mas ainda são escassas as imagens de indígenas e todas as fotos localizadas mostram representantes de diferentes etnias, seminus e com ornamentos típicos. A veiculação exclusiva dessa representação estereotipada dificulta e, talvez, impossibilite a construção de uma representação contemporânea de imagens de diferentes etnias ao longo da obra. A inclusão de fotografias atuais de pessoas indígenas tem se dado através da busca de um ser mítico tradicional, com atributos bastante positivos. Tais aspectos relacionam-se ao imaginário social sobre seres quase sobre-humanos, que preservavam o meio-ambiente natural, eram sábios e também poderosos em suas crenças xamânicas (MOTA, 2008). A imagem de um "verdadeiro" indígena tem sido divulgada por uma parcela da sociedade brasileira que se reconhece como não indígena. Essa visão aproxima-se muito da visão do “bom selvagem”, preconizada por Jean-Jacques 
Rousseau (MOTA, 2008). O indígena não deixa de ser indígena por viver em uma sociedade contemporânea e essas representações reforçam uma imagem estereotipada desses povos.

Quanto às ocupações das pessoas indígenas representadas nas coleções de livros do PNLD 2018, percebemos as seguintes categorias: três fotografias de agricultores, três de mulheres preparando beiju (alimento produzido a partir da mandioca), uma de pescadores e uma de mulher artesã. A representação do indígena como agricultor foi uma das ocupações mais recorrentes nas coleções de 2018, cabendo ressaltar que os indivíduos representados estão sempre executando as atividades de uma maneira que exige algum tipo de esforço físico, diferentemente do "homem" branco, representado desempenhando trabalhos intelectuais ou fazendo uso de tecnologias para executar suas atividades. Já a figura da mulher indígena é vinculada ao artesanato ou associada a alguma atividade doméstica, como a preparação de alimentos.

Existem profissionais indígenas atuando na implementação de políticas públicas sociais, educacionais e de saúde e também gerenciando projetos de indenização de empreendimentos hidrelétricos em territórios indígenas (AMARAL, 2014). Essa realidade poderia ser representada nos livros didáticos de modo a dar visibilidade aos efeitos de políticas de reparação.

Embora a identidade étnica esteja juridicamente definida a partir do conceito de autoidentificação e adscrição, essas populações se apercebem e se apresentam orientadas pela expectativa da população brasileira. Nela, os povos nativos teriam a aparência estereotipada e fixa do período colonial e, assim, pintam-se, fazem para si cocares e utilizam tangas. Apropriam-se, portanto, do estereótipo que nossa sociedade criou e participam dessa engrenagem normatizadora em que padrões sociais são concebidos, constantemente reforçados e reproduzidos (CARDOSO, 2017).

Quanto ao contexto das fotos em que aparecem pessoas indígenas, observam-se representações de diferentes práticas culturais, como rituais de iniciação, pinturas corporais, preparação de pratos típicos e produção de artesanato, como cestarias. Essas fotos foram categorizadas como "diversidade cultural". A categoria "amamentação" tem apenas uma foto com uma mãe e um bebê nus. Por fim, a categoria "paciente" mostra um homem indígena sendo vacinado por uma enfermeira branca. Nesta última representação, observa-se hierarquia entre a profissional da saúde, numa posição superior de sujeito da ação, e o paciente, objeto da ação. Reforça-se, assim, uma representação hierárquica entre brancos e indígenas. Ainda que a aplicação de uma vacina seja uma atividade técnica, há uma hierarquia entre o detentor do conhecimento técnico e o alvo da ação. Esta é a forma como a branquitude opera: a desigualdade é naturalizada 
e internalizada no cotidiano como o normal, não sendo percebidos os privilégios (CARDOSO, 2017).

Com relação às representações de pessoas indígenas em desenhos, foi possível classificálas em três categorias de contextos: desenhos anatômicos, em que órgãos internos do corpo humano são representados em imagens de pessoas com traços fisionômicos indígenas; diversidade genética, em que são apresentadas imagens sobre a composição do DNA e sobre hereditariedade e diversidade cultural, em que um desenho de mulher indígena é acompanhado de um texto sobre as explicações tradicionais dos povos autóctones para a origem da vida.

Embora tenham sido observadas fotos e ilustrações de indígenas, o número de representações ainda era muito pequeno (4\%). Observaram-se 19 fotografias, sendo 16 adultos e três crianças. Das 16 fotos de adultos, 11 eram de homens e cinco de mulheres. Entre as três fotos de crianças, uma era de menino e duas de meninas de diferentes etnias.

Além de ocorrer um aumento no número de pessoas negras e indígenas em 2018, quando comparado às obras dos anos anteriores, observamos também mudanças na forma como as pessoas negras foram representadas. Como exemplo, ampliou-se o número e o tipo de representações do gênero feminino, nas quais a mulher passou a ocupar posições de maior prestígio social (DUBAR, 2012). Acreditamos que essas mudanças estão relacionadas aos critérios do PNLD 2018, que indicavam a promoção da equidade de gênero. Porém, cabe observar que não foi localizada nenhuma imagem que permitisse identificar alguma pessoa, de qualquer origem étnica, como transgênero ou homossexual nos livros analisados. Ficando, então, descumprido o critério que busca combater a homo e a transfobia no que diz respeito às imagens.

A coleção de Lopes e Rosso (2017), publicada pela editora Saraiva, conta com 31 fotografias, sendo 12 fotos (39\%) de pessoas negras, destacando-se como a coleção com maior quantidade de imagens de pessoas negras. Ainda assim, esse percentual não corresponde à proporção de negros da população brasileira, ficando aquém dos dados divulgados pelo Instituto Brasileiro de Geografia e Estatística (IBGE) em 2017, que apontam que um pouco mais da metade da população brasileira se autodeclarou negra.

Segundo a Pesquisa Nacional por Amostra de Domićlios (PNAD) de 2019, realizada pelo Instituto Brasileiro de Geografia e Estatísticas (IBGE), constatou-se que 54\% da população é de pretos ou pardos (grupos agregados na definição de negros). A cada dez pessoas, três são mulheres negras. Tais dados representam um aumento de $15 \%$ entre aqueles que se autodeclaram negros/as, quando comparado ao último censeamento, realizado em 2010. De acordo com pesquisadores do próprio Instituto, a expansão na autodeclaração de pretos está relacionada ao reconhecimento da 
população negra em relação à própria cor, o que faz com que mais pessoas se identifiquem como pretas.

Desde então, o número de pessoas que se diz negra ou parda amplia-se, movimento que está relacionado à visibilidade que tem sido dada à temática racial nos últimos anos. Assim, possibilita-se a apropriação, a desconstrução e a reconstrução que reformulam questões relacionadas à identidade e corrobora-se o processo que vem sendo conceituado como etnogênese. Trata-se de um fenômeno no qual, diante de determinadas circunstâncias históricas, um grupo étnico, que havia deixado de assumir sua identidade étnica por razões também históricas, consegue reassumi-la e reafirmá-la, recuperando aspectos relevantes de sua cultura tradicional (LUCIANO, 2006).

Até 1850 , não se falava em raça e o negro poucas vezes era tema da literatura ou de trabalhos científicos. A introdução do racismo científico no Brasil, no século XIX, levou à formação de uma imagem depreciativa que chegou até à produção cultural e aos meios de comunicação. Utilizado pelas elites nacionais como justificativa para um imperialismo local, pois, ao adotar doutrinas europeias, o País estaria em um suposto progresso civilizatório. Conforme dados históricos, os africanos eram descritos como negligentes, passivos, embrulhões e guiados pelo impulso. Os europeus, ao contrário, tidos como inteligentes, inventivos e guiados pelas leis, "[...] com uma tendência a estabelecer hierarquias de valores no interior das quais os europeus se saem sempre bem, ou mesmo muito bem” (BARBUJANI, 2007, p. 66).

Durante a Segunda Guerra Mundial, Ashley Montagu havia escrito que, no homem, a raça é uma construção social e não um dado biológico (BARBUJANI, 2007). No entanto, mesmo assim as sociedades humanas construíram elaborados sistemas que privilegiam alguns e oprimem outros. Dessa forma, a branquitude detém uma posição assimétrica em relação a todos os outros termos raciais e culturais, por razões cujas origens são coloniais (RIBEIRO, 2004).

Os lugares de representação simbólica - como espaços públicos, livros didáticos, produções artísticas e meios de comunicação - grande parte das vezes tendem a reproduzir a segregação presente nos demais setores da sociedade. O branco é historicamente (auto)representado como o ser humano ideal e essas representações contribuem significativamente para a manutenção dos privilégios da branquitude, maior beneficiária do racismo presente em nossa sociedade até os dias atuais.

Analisando os dados oficiais do IBGE 2018, naquilo que remete à totalidade de habitantes declarados indígenas, verificamos a existência de pelo menos um indígena autodeclarado em 80,5\% dos municípios brasileiros. O critério utilizado para a captação dos indígenas nos censos 
demográficos foi a autoclassificação ou autoidentificação, independentemente de quem foi o informante, o próprio ou não. Portanto, a população indígena não chega a um ponto percentual, totalizando 0,4\% da população total brasileira (IBGE, 2018). Em alguma medida, acreditamos que essa população é subdeclarada por motivos diversos, tais como o estigma construído ao longo dos séculos da história do Brasil, sobretudo o preconceito construído ao redor da ideia de "ser índio". É importante ressaltar que a categoria "indígena" foi introduzida no questionário do censo demográfico em âmbito nacional apenas em 1991. Anteriormente, a categoria estava subsumida no quesito cor e aplicava-se apenas aos que viviam em aldeamentos ou postos indígenas, excluindo os que foram expulsos de seus territórios tradicionais.

A ampliação do acesso à escolarização, apoiada nos instrumentos e orientações já descritos, pode contribuir para a redução de crenças e posturas racistas e preconceituosas que afetam o discurso e a prática pedagógica. Dessa forma, contribui-se para favorecer o reconhecimento da diversidade como característica essencialmente humana e reparar equívocos e dívidas históricas com negros e indígenas. É preciso descolonizar os currículos e a escola (GOMES, 2017).

O conhecimento e a valorização exclusiva de elementos pertencentes a sua própria cultura, assim como os estereótipos acerca das culturas alheias, fazem parte dos mecanismos que dão origem e sustentação ao preconceito e à discriminação, aqui entendidos como instâncias distintas, mas que se retroalimentam de forma a garantir a manutenção e a reprodução do racismo.

Diante da pergunta norteadora de pesquisa, a qual buscou verificar o cumprimento de critérios estabelecidos pelos editais do PNLEM 2009 e PNLD 2018, no que tange à promoção da equidade étnico-racial nos livros didáticos, pudemos observar que ocorreu um avanço na representação dos povos indígenas e afro-brasileiros que passaram a ocorrer de forma mais positiva e com maior destaque nos livros aprovados pelo edital de 2018 quando comparados aos produzidos anteriormente e após a publicação do edital de 2007. Porém, essa representação ocorre em quantidade inferior quando comparado ao número de imagens que contenham indivíduos brancos e desse modo, de maneira que não contempla a equidade racial.

\section{Considerações finais}

A análise de livros didáticos de Biologia publicados antes e depois da implementação dos programas de avaliação de obras adquiridas e distribuídas às escolas públicas pelo Ministério da Educação indica a importância da existência de critérios de exclusão de obras que descumprem o artigo 26-A da LDBEN (1996) o qual tornou obrigatório o estudo das culturas e da história de africanos, afro-brasileiros e indígenas. Antes do edital de 2007 que orientou a seleção de obras de 
Biologia, distribuídas em 2009, não foram localizadas imagens de pessoas negras e indígenas nos livros analisados.

A redação do primeiro edital de 2007, indicando que livros que difundissem preconceitos e discriminação seriam excluídos das compras do Ministério, não foi suficiente para garantir a representação da pluralidade da população brasileira e a veiculação de imagens positivas e não estereotipadas de negros e indígenas. Assim, a inclusão dessas exigências, no texto do edital de 2018, teve um efeito positivo na produção de livros didáticos, indicando a importância de políticas públicas que garantam o cumprimento da regulamentação legal.

Observou-se também que o mercado editorial está sujeito ao racismo estrutural e que por isso são necessárias pressões sociais, mecanismos legais e políticas públicas que sejam produzidas com a intenção de combater o racismo. Mas o cumprimento legal ainda não é suficiente uma vez que a expressão da pluralidade brasileira exigiria que mais da metade das imagens fossem de pessoas negras para expressão da realidade nacional, e não os $26 \%$ localizados.

Com relação à representação dos povos indígenas ainda que 5\% das imagens fossem referentes a grupos que perfazem menos de $1 \%$ da população, ela parece insuficiente, justamente devido aos processos de genocídio históricos intensificados nos últimos anos. Além disso, observamos que as representações são ainda estereotipadas de maneira que o previsto no edital de 2018 não foi cumprido integralmente. Assim, há um espaço de trabalho para uma educação de valorização da diversidade cultural a ser feito pelas instituições educacionais e professores.

A valorização da diversidade tem de ocorrer com várias estratégias durante a rotina escolar e de forma contínua, partindo do pressuposto de que não há padrões referenciais de individualidade, personalidade, imagem, beleza ou mesmo de conhecimento e comportamento. Essa perspectiva de educação intercultural altera positivamente os livros e a escola, bem como evidencia a complexidade da humanidade e leva ao reexame da cultura escolar.

A positivação da imagem torna aparente atributos que nos distinguem, provocam nossa própria valorização e a empatia no outro. A representatividade inspira, encoraja, fortalece os laços com nossa própria ancestralidade. Dessa forma, é possível aprender e ensinar em conjunto com seu semelhante para que de maneira coletiva sejamos capazes de construir uma sociedade plural, justa e igualitária para todos. 


\section{Referências}

AMARAL, Wagner Roberto do; RODRIGUES, Michelle Aparecida; BILAR, Jenifer Araujo Barroso. Os circuitos de trabalho indígena: possibilidades e desafios para acadêmicos e profissionais Kaingang na gestão das políticas públicas. Mediações-Revista de Ciências Sociais, Londrina, v. 19, n. 2, p. 129-145, 2014. Disponível em: http://dx.doi.org/10.5433/21766665.2014v19n2p129 Acesso em: 14 mar. 2021.

AMORIM, Diego Uchoa. Teorias raciais no Brasil: um pouco de história e historiografia. Revista Cantareira, São Paulo, n. 19, 5 fev. 2019. Disponível em:

https://periodicos.uff.br/cantareira/article/view/27725. Acesso em: 15 abr. 2021.

BARBUJANI, Guido. A invenção das raças: Existem mesmo raças humanas? Diversidade e Preconceito Racial. São Paulo: Editora Contexto, 2007.

BENTO, Maria Aparecida da Silva et al. (Org.). Psicologia social do racismo: estudos sobre branquitude e branqueamento no Brasil. Petrópolis: Vozes, 2002.

BRASIL. Presidência da República. Casa Civil. Subchefia para Assuntos Jurídicos. Lei n. 7.437, de 20 de Dezembro de 1985. Diário Oficial da União, Brasília, 1985. Disponível em: http://www.planalto.gov.br/ccivil_03/leis/L7437.htm. Acesso em: 08 abr. 2021.

BRASIL. Ministério da Educação. Secretaria de Educação Básica. Fundo Nacional de Desenvolvimento da Educação. Programa Nacional do Livro Didático para o ano de 2007. Brasília: Ministério da Educação, Secretaria de Educação Básica, 2007. Disponível em: http://www.fnde.gov.br/programas/programas-do-livro/consultas/editais-programaslivro/item/3014-editais-anteriores. Acesso em: 08 abr. 2021.

BRASIL. Lei no 11.645, de 10 de Março de 2008. Altera a Lei no 9.394, de 20 de dezembro de 1996, modificada pela Lei no 10.639, de 9 de janeiro de 2003, que estabelece as Diretrizes e Bases da Educação Nacional, para incluir no currículo oficial da rede de ensino a obrigatoriedade da temática "História e Cultura Afro-Brasileira e Indígena". Diário Oficial da União, Brasília, 2008a. Disponível em: http://www.planalto.gov.br/ccivil_03/_Ato2007-

2010/2008/Lei/L11645.htm\#art1. Acesso em: 04 mar. 2021.

BRASIL. Secretaria de Educação Básica. Fundo Nacional de Desenvolvimento da Educação. Biologia: Catálogo do Programa Nacional do Livro para o Ensino Médio: PNLEM/2009. Brasília: Ministério da Educação, Secretaria de Educação Básica, 2008b. 108 p. Disponível em: http://www.fnde.gov.br/component/k2/item/4289-guia-pnlem-2009. Acesso em: 02 mar. 2021.

BRASIL. Ministério da Educação. Secretaria de Educação Básica. Fundo Nacional de Desenvolvimento da Educação. PNLD 2018: Biologia - Guia de Livros Didáticos - Ensino Médio. Brasília: Ministério da Educação, Secretária de Educação Básica, 2017. 92 f. Disponível em: http://www.fnde.gov.br/pnld-2018/. Acesso em: 02 mar. 2021.

CARDOSO, Lourenço. Retrato do branco racista e anti-racista. Reflexão e Ação, Santa Cruz do Sul, v. 18, n. 1, p. 46-76, 2010. Disponível em: http://dx.doi.org/10.17058/rea.v18i1.1279 Acesso em: 26 mar. 2021. 
CARDOSO, Lourenço; MULLER, Mara. Branquitude: estudos sobre a identidade branca no Brasil. Curitiba: Appris, 2017.

DUBAR, Claude. A construção de si pela atividade de trabalho: a socialização profissional. Cadernos de pesquisa, São Paulo, v. 42, n. 146, p. 351-367, 2012. Disponível em: https://doi.org/10.1590/S0100-15742012000200003 Acesso em: 26 mai. 2021.

FREIRE, Paulo. A imagem do índio e o mito da escola. In: MARFAN, Marilda A. (Org.). Congresso Brasileiro de Qualidade na Educação - Formação de Professores: educação escolar indígena. Brasilia: MEC, 2002.

GOMES, Nilma Lino. O Movimento Negro educador: saberes construídos nas lutas por emancipação. Petrópolis: Vozes, 2017.

IBGE. Instituto Brasileiro de Geografia e Estatística. PNAD Contínua Educação 2019. Rio de Janeiro, 2018. Disponível em: https://agenciadenoticias.ibge.gov.br/agencia-sala-deimprensa/2013-agencia-de-noticias/releases/28285-pnad-educacao-2019-mais-da-metade-daspessoas-de-25-anos-ou-mais-nao-completaram-o-ensino-medio. Acesso em: 17 abr. 2021.

LOPES, Sônia; ROSSO, Sergio. BIO. 3 volumes. São Paulo, SP: Saraiva, 2017.

LUCIANO, Gersem dos Santos. O indio brasileiro: o que você precisa saber sobre os povos indígenas no Brasil de hoje. Brasília: Ministério da Educação; Secretaria de Educação Continuada, Alfabetização e Diversidade; Museu Nacional, Laboratório de Pesquisas em Etnicidade, Cultura e Desenvolvimento, 2006.

MARTINS, Carlos Augusto. Racismo anunciado: o negro e a publicidade no Brasil (1985-2005). São Paulo: USP, 2009.

MOTA, Clarice. Ser indígena no Brasil Contemporâneo, novos rumos para um velho dilema. Ciência e Cultura, São Paulo, v. 60, n. 4, 2008. Disponível em:

http://cienciaecultura.bvs.br/scielo.php?pid=S0009-67252008000400011\&script=sci_arttext. Acesso em: 10 mar. 2021.

RIBEIRO, Vera. Branquidade: identidade branca e multiculturalismo. Rio de Janeiro: Garamond, 2004.

ROMÃO, Jeruse. O educador, a educação e a construção de uma auto-estima positiva no educando negro. In: CAVALLEIRO, Eliane (Org.). Racismo e anti-racismo na educação: repensando nossa escola. São Paulo: Selo Negro, 2001.

SILVA, Ana Célia da. A discriminação do negro no livro didático. Salvador: Centro Editorial Didático; Centro de Estudos Afro-Orientais, 1995.

SILVA, Ana Célia da. Desconstruindo a discriminação do negro no livro didático. Salvador: EDUFBA, 2001.

VERRANGIA, Douglas; SILVA, Petronilha B. G. Cidadania, relações étnico-raciais e educação: desafios. Educação \& Pesquisa, São Paulo, v. 36, n. 3, p. 705-718, 2010. Disponível em: https://doi.org/10.1590/S1517-97022010000300004 Acesso em: 14 abr. 2021. 